\title{
PARA SER UM SER NO MUNDO: A HUMANIZAÇÃO É UMA POÉTICA EM PAULO FREIRE
}

Aristóteles Berino ${ }^{(*)}$

Recuperar os bens que sempre foram usurpados, equivale a recuperar o destino Eduardo Galeano (1994, p. 19)

Oito de dezembro de 1982. Naquele dia, em Estocolmo, Gabriel García Márquez recebia das mãos dos reis da Suécia o Prêmio Nobel de Literatura. Apesar do suposto reconhecimento universal do prêmio, Gabriel García Márquez não deixou escapar a oportunidade para assinalar a problemática do poder entre os hemisférios norte e sul do planeta. Seu discurso, intitulado A solidão da América Latina, foi uma observação sobre o direito do continente à autodeterminação política e à alteridade do conhecimento diante de outras sociedades. Disse Gabriel García Marquez (2011, p. 26): “A interpretação da nossa realidade a partir de esquemas alheios só contribui para tornar-nos cada vez mais desconhecidos, cada vez menos livres, cada vez mais solitários".

As palavras de Gabriel García Márquez, pronunciadas na Europa, estabelecem uma identidade diante do estrangeiro, mas constituem principalmente para nós mesmos, latinoamericanos, uma pedagogia. A afirmação de Gabriel García Márquez reivindica uma singularização que nos situa em um campo epistemológico aberto a concepções disruptivas, em um horizonte renovado de possibilidades cognitivas em que o ato mesmo de pensar é um desfronteiramento: "Nós, os inventores de fábulas que acreditamos em tudo, nos sentimos no direito de acreditar que ainda não é demasiadamente tarde" (ibidem, p. 28). Os "inventores de fábulas", os que fazem literatura, mas não apenas, entendo. Na verdade, todos os que "acreditam em tudo", ou seja, todos que fazem da atividade do pensamento uma submissão do real à capacidade criadora da imaginação.

Reclamando a autonomia das sociedades americanas para tecer a sua existência, reconstruindo suas histórias, Gabriel García Márquez declara ainda, no final do seu discurso, a respeito de uma utopia que nos fará desviar de um destino traçado fora das nossas terras: “onde de verdade seja certo o amor e seja possível a felicidade, e onde as estirpes condenadas a cem anos de solidão tenham, enfim e para sempre, uma segunda oportunidade sobre a terra" (ibidem, p. 28). Utopia que significa a pretensão de uma outra realidade, diferente de tudo que foi até agora

(*) Professor do Departamento de Educação e Sociedade da Universidade Federal Rural do Rio de Janeiro (DES/UFRRJ/Nova Iguaçu) e do Programa de Pós-graduação em Educação, Contextos Contemporâneos e Demandas Populares (PPGEduc/UFRRJ).E-mail: berino@ufrrj.br. 
concebido para nós, latino-americanos, contra as nossas vivências e necessidades. Uma "segunda oportunidade" como a perseguição de caminhos autênticos, orientados pela independência política, visão de mundo inseparável da fantasia, da capacidade de existir fabulando a própria vida, mesmo que causem assombro naqueles que sempre usufruíram da nossa subalternidade e acomodação.

O que pretendo discutir neste artigo é a relevância da obra de Paulo Freire para a formulação de alternativas latino-americanas aos projetos de sociedade que nos constrangem à perseguição de roteiros já delimitados e que afligem a nossa soberania. Uma obra que conflita com as práticas de dominação que primariamente beneficiam interesses localizados em territórios longínquos, mas desde há muito estabelecidas também em nosso continente através das desigualdades sociais, uma rede de poder mundializada e associada que contrai a nossa viabilidade de atingir, como diria o educador Miguel Arroyo (2017), uma "vida justa". Acredito existir no legado de Paulo Freire uma significativa contribuição à reivindicação decolonial de uma "epistemologia do Sul" (SANTOS, 2010), uma concepção de teoria do conhecimento que transgride com a colonialidade cognitiva que restringe a contextualização da nossa própria existência.

Iniciando com uma questão elementar: Por que voltar à Paulo Freire agora, vinte anos após a sua partida? Personagem da história latino-americana no século XX, nascido em 1921 e morto em 1997, Paulo Freire mantém-se como um intelectual influente, até hoje lembrado quando se trata de discutir não apenas políticas educacionais, mas ainda o problema da ação cultural para a liberdade (FREIRE, 1987). A questão da formação em Paulo Freire é mais ampla do que a experiência estritamente escolar. A chamada "conscientização" (FREIRE, 2016) que aparece em seus escritos é uma aquisição social mais vasta do que as retribuições atribuídas à escola. Para Paulo Freire, a educação é uma prática fundamental para "ser um ser no mundo" (FREIRE apud FREIRE, 2017, p. 237), uma condição para a existência de indivíduos plenamente perceptivos de sua humanidade apesar das diferentes situações em que concretamente vivem.

Crítico das condições globais do poder capitalista e pós-colonial, Paulo Freire escreveu e agiu em favor de populações oprimidas, grupos sociais explorados e coletivos discriminados. Dedicou-se a isso não apenas no Brasil, mas também em outros países, no continente americano e africano, e ainda nos Estados Unidos e na Europa. Em todos os trabalhos que desenvolveu como educador, Paulo Freire deparou-se com a necessidade de conceber práticas educativas transformativas, com as quais pudéssemos interpretar as condições de nossas vidas como históricas e, assim, possíveis de mudanças. A condição para "ser um ser no mundo" não é uma revolução pessoal, mas uma diligência cuja possibilidade só existe como articulação coletiva. A educação é, 
assim, um agir para o comum, concebida para uma experiência necessariamente dialógica porque referida ao que é plural.

A utopia que nos fala Gabriel García Márquez encontra no conceito do "inédito viável” de Paulo Freire uma atualização teórica válida quando pretendemos ser sociologicamente convincentes ao falarmos da transformação das sociedades latino-americanas sem, no entanto, dispensarmos os atributos mais poéticos originalmente concebidos: "onde de verdade seja certo o amor e seja possível a felicidade”. O inédito-viável de Paulo Freire (2006, p. 108) na sua pedagogia do oprimido é um conceito que se refere a um estado possível de realizações depois de superadas as "situações-limites" que restringem nossa visão de mundo a perspectivas existencialmente limitadas. A ação cultural que constitui a educação freireana se constitui como um movimento social libertador, um desembaraço para que a nossa leitura de mundo resulte em uma expansão do nosso horizonte vital.

A primeira etapa do chamado "Método Paulo Freire" é uma pesquisa sobre o universo vocabular dos alfabetizandos. Os educadores primeiro procuram saber quais palavras fazem parte das vivências cotidianas e regulares desses educandos. As palavras descobertas são as palavras geradoras que serão usadas no processo de alfabetização do grupo. Diferente das palavras usadas nas cartilhas padronizadas de alfabetização, as palavras geradoras estão implicadas com a vida social dos alfabetizandos e desse modo são mobilizadoras de suas existências. As palavras geradoras manifestam os temas geradores que podem preservar o caráter de educação propriamente popular. Como observou Carlos Rodrigues Brandão (1996, p. 22), “quem dá a palavra dá o tema, quem dá o tema dirige o pensamento, quem dirige o pensamento pode ter o poder de guiar a consciência".

A opção pelos temas geradores extraídos das situações existenciais dos educandos é um engajamento cultural da educação popular. O educador situa-se ao lado da história social de seus educandos no lugar de posicionar-se verticalmente, olhando de cima para baixo, a partir de uma estrutura hierarquizada dos saberes - e, portanto, dos sujeitos. A educação como prática da liberdade (FREIRE, 1994) é uma ruptura com as concepções domesticadoras do conhecimento, de interesse local das classes dominantes, mas também de interesse mundializado porque são as mais adequadas à manutenção da ordem política e econômica internacional que procura manter as classes populares subalternizadas enquanto o próprio país figura de forma dependente e submissa na globalização capitalista. De outro modo, portanto, o encontro pedagógico que fortalece as classes populares é aquele em que "o educador já não é o que apenas educa, mas o que, enquanto educa, é educado, em diálogo com o educando que, ao ser educado, também educa” (FREIRE, 2006, p. 79). 
Para ser um "ser no mundo" desde as sociedades latino-americanas é preciso colocar o problema do conhecimento também como um problema de libertação, construindo epistemologias que permitam significar a existência das nossas sociedades de acordo com os interesses das populações que pretendem autonomia e não subordinação. Uma pedagogia para que as classes populares se engrandeçam através dos recursos das suas experiências e dos seus saberes. Educação em que as atribuições de educador e de educando não são fixas, mas em que os respectivos "papéis" são intercambiáveis, uma relativa equivalência para que efetivamente os problemas vividos política e socialmente pelas classes populares alcancem a centralidade necessária à prosperidade da conscientização e da mudança social. É assim uma educação libertadora porque a autonomia da classes populares é a única via teórica e prática que confronta seus dilemas e move-se no sentido da sua emancipação.

A educação amplia nossas possibilidades, na perspectiva freireana, não porque nos prepara adequadamente para a vida em geral, socialmente indeterminada. Ainda que cada etapa escolar vencida proporcione alguma vantagem virtualmente superior, não é essa a política educativa de Paulo Freire. O discurso normalizador sobre a educação se atém no proveito pessoal e socialmente indistinto que pode assegurar. No entanto, o modo como os indivíduos existem como personagens sociais em uma estrutura desigual que perpetua a diferença não é problematizada senão de forma calculada para que não motive drástica insatisfação e irrupção contra o sistema. A condição social deve não apenas permanecer satisfatoriamente intacta, mas inatingível como realidade a ser imaginada como modificável. No entanto, urdir o inédito-viável é exatamente constatar, diz Ana Maria Araújo Freire (2008, p. 233), “que não há o reino do definitivo, do pronto e do acabado; do nirvana da certeza e da quietude dos sonhos possíveis".

A educação pensada com Paulo Freire é factualmente desestabilizadora. O trabalho educativo desenvolvido a partir dos temas geradores consiste em um diálogo crítico expansivo da nossa compreensão a respeito de como a nossa vida é constituída. Uma fronteira cognitiva é cruzada quando discutimos os condicionamentos históricos e sociais das nossas situações existenciais. As "situações-limites" vão se desvanecendo e o que antes não era concebido para a assunção da nossa presença no mundo passa a compor a imaginação e as ações como um "inéditoviável”. A razão política da concepção freireana de educação é o entendimento de que "ser um ser no mundo" é simultaneamente uma necessidade e uma possibilidade. "Somos seres condicionados mas não determinados", diz Paulo Freire (2015, p. 20), uma premissa fundamental para a concepção de uma epistemologia disruptiva com o pensamento social dominante. 
Apesar dos riscos que cercam a noção de utopia, já que é muitas vezes acusada de corresponder ao oposto de uma concepção seguramente orientada para uma sociedade que se deseja mudar, o desejo imaginativo por uma vida mais esperançosa e promissora para nós, latinoamericanos, do mesmo modo como aparece no discurso de Gabriel García Márquez quando recebeu o Prêmio Nobel de Literatura, também foi assumido por Paulo Freire como um sonho arrebatador. Disse Paulo Freire (2000, p. 54), “os sonhos são projetos pelos quais se luta”. O que nos faz muitas vezes relacionar nossas expectativas à utopia ou ao sonho deve-se à distância do que queremos em relação à realidade atual. As condições criadas no continente latino-americano a partir da colonização, do imperialismo e da atual globalização pesam como irremediáveis, como indefinidamente cem anos de solidão. Portanto, outra América Latina parece apenas existir como um absurdo, limitado à categoria ilusória da utopia e à evasão escapista do sonho.

Mas Paulo Freire não articulava à utopia ou ao sonho uma visão de mundo inconsequente, pelo contrário. "Mulheres e homens podem mudar o mundo para melhor, para fazê-lo menos injusto, mas a partir da realidade concreta a que 'chegam' em sua geração”, lembrou Paulo Freire (ibidem, p. 53), em um texto que escreveu para afirmar o direito e o dever que temos de mudar o mundo. Inexistindo uma determinação absoluta que nos impeça de transformar as nossas realidades, locais ou até em uma escala global, existem, no entanto, condicionamentos que não devem ser ignorados. Não é o caso de sonhar de modo instituído e ajustado, mas admitir que as maiores ambições exigem o pensamento e a prática articulados a um rigor de libertação. As utopias, sejam quais forem, dependem tanto das propriedades tangíveis da "realidade concreta" quanto da nossa capacidade de ser sublime ao pensar outras realidades.

Enfatizo que educação em Paulo Freire não corresponde à concepção de uma "preparação para a vida" no sentido de formar para um ajuste social já estabelecido e definitivo nos seus elementos fundamentais. O imaginário social convencional sobre a educação é conservador e muitas vezes conformista a respeito da sua destinação. A criança ingressa na escola para ser dotada de uma capacidade pessoal superlativa que supostamente lhe permitirá uma posição social privilegiada, reproduzindo as condições familiares herdadas ou avançando sobre elas para atingir um patamar superior. Mas a imagem da educação como uma "bagagem" que um aprendiz leva consigo para usos sucessivos ao longo da vida e com a qual responde oportunamente e idealmente de modo favorável a diferentes desafios entre objetivos pessoais e necessidades coletivas, é, antes de tudo, uma mistificação ideológica sobre as suas “oportunidades”. Trata-se da concepção de educação caracteristicamente adaptativa que orienta a montagem dos sistemas escolares nacionais com o advento do capitalismo. 
Para Paulo Freire, a educação é, sobretudo, uma prática transformadora. Em Educação como uma prática da liberdade, lembrando a trajetória desenvolvida no início dos anos 60 com o Movimento de Cultura Popular de Recife e com o Serviço de Extensão Cultural da Universidade de Recife até a consolidação do seu "Método", observará Paulo Freire (1994, p. 112): "pensávamos numa alfabetização que fosse em si um ato de criação, capaz de desencadear outros atores criadores". A vivência da prática educativa tal como Paulo Freire a concebeu é uma apropriação do mundo, isto é, uma sucessiva apropriação da realidade humana socialmente construída. Porventura, uma existência apenas casualmente percebida adquire uma extensão problematizadora. Progressivamente, a partir de uma realidade mais imediata até a sua localização na dimensão mais ampla da história social das sociedades, a existência adquire ambições mais valorativas da sua presença no local, na cidade, até a geografia política do planeta.

Trata-se de uma apropriação criadora porque o ato educativo corresponde aqui a uma leitura do mundo a partir da qual reposicionamos nele a nossa presença. Nas palavras de Paulo Freire (2011, p. 29), "a leitura do mundo precede sempre a leitura da palavra e a leitura desta implica a continuidade da leitura daquela". Claro, o educando não se insere raso em uma prática educativa qualquer. Ela já faz, através da sua experiência existencial, uma leitura do mundo. Quando Paulo Freire refere-se à "leitura da palavra" está se referindo à alfabetização. Contudo, é perfeitamente cabível considerá-la também como referida à educação de um modo geral. Portanto, "leitura da palavra" como domínios sucessivos da prática do conhecimento. Com a "leitura da palavra", a leitura do mundo se complexifica e o ato criador da educação adquire possibilidades transformativas mais significativas. O mundo é percebido conhecendo a natureza social que constitui a sua realidade, desvelando os princípios do poder entre as classes sociais, sobretudo.

A dedicação à conquista de uma "vida justa" coloca-nos o desafio da transformação, que para Paulo Freire é algo sempre atrativo e visionário porque a educação é vista como uma prática solidária e esperançosa. Solidária uma vez que o encontro entre educadores e educandos vitaliza seus participantes com a descoberta de que a existência é resultado do que lhe atribuímos social e historicamente. A condição da existência é uma trama que podemos investigar e alterar juntos. A concepção de educação em Paulo Freire é assim entusiasmada pelas pessoas e pelo que podem fazer comprometidas. Do mesmo modo, é esperançosa. Não é a esperança que resulta de uma espera qualquer por dias melhores, mas a esperança cultivada que nasce da confiança na luta que pode mobilizar tantas e tantas pessoas em favor da mudança porque são muitos os afrontados pelo poder. Além da sua razão sociológica, a rebeldia revolucionária é feita de aproximação política e prometedora alternativa. 
Se o pensamento utópico muitas vezes nos permite evocar a proporção plástica com a qual também tecemos a nossa visão do mundo, também é verdade que a natureza da escrita, isto é, a forma literária, poderá intensificar seus elementos estéticos e criativos. Existem algumas poucas poesias conhecidas escritas por Paulo Freire. Uma delas é de interesse para este artigo. Em março de 1971, em Genebra, na Suíça, Paulo Freire (2000, p. 5) encontrará no gênero da poesia um oportuno meio de expressão:

\section{CANÇÃO ÓBVIA}

Escolhi a sombra desta árvore para

repousar do muito que farei, enquanto esperarei por ti.

Quem espera na pura espera vive um tempo de espera vã.

Por isto, enquanto te espero

trabalharei os campos e

conversarei com os homens.

Suarei meu corpo, que o sol queimará;

minhas mãos ficarão calejadas;

meus pés aprenderão o mistério dos caminhos;

meus ouvidos ouvirão mais,

meus olhos verão o que antes não viam,

enquanto esperarei por ti.

Não te esperarei na pura espera

porque o meu tempo de espera é um

tempo de quefazer.

Desconfiarei daqueles que virão dizer-me

em voz baixa e precavidos:

É perigoso agir

É perigoso falar

É perigoso andar

É perigoso esperar, na forma em que esperas,

porque esses recusam a alegria de tua chegada.

Desconfiarei também daqueles que virão dizer-me,

com palavras fáceis, que já chegaste,

porque esses, ao anunciar-te ingenuamente,

antes te denunciam.

Estarei preparando a tua chegada

como o jardineiro prepara o jardim

para a rosa que se abrirá na primavera. 
Canção Óbvia foi escrita aproximadamente um ano após Paulo Freire chegar à Europa para seguir o seu exílio na Suíça, onde permaneceu até 1980, quando finalmente retornou ao Brasil. Ainda no ano de 1964, alguns meses após o golpe de estado de 31 de março que afastou o presidente João Goulart, depois de duas prisões e uma terceira que logo seria consumada, Paulo Freire saiu do Brasil para a Bolívia e logo depois para o Chile. Depois de uma significativa experiência ali desenvolvida com alfabetização no campo, em 1968 muda-se para os EUA, para lecionar em Harvard. De lá, ainda no início de 1970, aceita um trabalho no Conselho Mundial das Igrejas - CMI, organização ecumênica fundada em Amsterdã e com sede em Genebra. É importante observar o contexto biográfico de Paulo Freire e histórico da ditadura militar no Brasil quando escreveu Canção Óbvia.

Em 1963, Paulo Freire organizou e dirigiu a campanha de alfabetização de Angicos, no Rio Grande do Norte. A experiência de Angicos, com resultados considerados excepcionais, adquiriu contornos míticos e passou a ocupar um lugar absolutamente central na biografia de Paulo Freire. Logo em janeiro do ano seguinte, decreto do presidente João Goulart institui o Programa Nacional de Alfabetização e determina o uso do "Sistema Paulo Freire" para a sua consecução. Anos mais tarde, em uma entrevista ao jornal O Pasquim, em 1978, Paulo Freire assim especulava sobre os possíveis impactos do Programa: "O que poderia ocorrer é que para a sucessão presidencial poderíamos ter no processo eleitoral, já que a lei não admitia o voto do analfabeto, facilmente 5 ou 6 milhões de novos eleitores" (apud FREIRE, 2017, p. 146). O já mencionado golpe de estado frustra as expectativas de Paulo Freire com o Programa de Alfabetização.

Paulo Freire entendia a educação como uma política de emancipação e consequentemente acreditava na sua importância para a democratização da sociedade brasileira. Desde antes da publicação do seminal Pedagogia do oprimido, em Educação e atualidade brasileira, tese que escreveu para o concurso de professor de História e Filosofia da Educação na Escola de Belas-Artes de Pernambuco, e em Educação como prática da liberdade, Paulo Freire já formulava a centralidade da educação - não de qualquer "educação", mas de determinada concepção de educação - para um projeto de nação. Ainda no final dos anos 50, afirma Paulo Freire (2002, p. 92): “A emersão do povo na vida nacional está a exigir toda uma revisão em nosso arcaico sistema educacional”. Em 1965, no Chile, insiste Paulo Freire (1994, p. 93/94): “A contribuição a ser trazida pelo educador brasileiro à sua sociedade em 'partejamento', ao lado dos economistas, dos sociólogos, como de todos os especialistas voltados para a melhoria dos seus padrões, haveria de ser a de uma educação crítica e criticizadora". 
O golpe de 1964 obrigou Paulo Freire ao exílio, abortando sua notável trajetória de educador na alfabetização de adultos e participação política na vida nacional. Seguirá trabalhando e escrevendo, em outros países, em outras realidades. Paulo Freire se tornará um pensador da educação incontornável nas últimas décadas do século $\mathrm{XX}$, reconhecido mundialmente, hoje sabemos. Contudo, bem ali no começo dos anos 70, poucos anos após o golpe, chegando à Europa sem sequer possuir um passaporte, que lhe era negado pela ditadura militar, tudo o que vislumbrava para a sociedade brasileira com uma educação transformadora encontrava-se agora em suspense. Sua própria existência encontrava-se interrompida. Canção óbvia foi escrita diante desse impasse sobre suas implicações com o que ocorria politicamente no Brasil. O texto traduz, talvez pudéssemos afirmar, uma angústia, mas não uma paralisia sobre o momento.

Apesar da necessária espera, Paulo Freire recusa a ideia de uma "pura espera". Pelo contrário, anuncia a atividade criadora como um princípio da esperança. A inevitabilidade de espera não impõe uma atitude de expectativa sobre o que se deseja. "Suarei meu corpo, que o sol queimará". Uma utopia precisa arder e o corpo será a sede de novos saberes que apenas o tempo faz nascer. Tato, visão, audição... Existirá a aurora tão somente quando seus sentidos puderem perceber concretamente a sua chegada. Sonhar, como propôs Paulo Freire, tem uma dimensão estética que a nós, latino-americanos, não convém sacrificar em favor de uma ciência puramente realista porque o “quefazer” freireano não sossega o nosso desejo por uma outra vida que vá além do imaginário permitido pelo poder. Notem a posição equilibrada que recusa tanto o receio da busca quanto a ingenuidade de uma procura pouco esclarecida. Mas notem ainda que para "ser um ser no mundo" é preciso redimensionar a nossa existência enquanto recriamos o espaço humano no planeta, humanizando-nos sempre poeticamente. 


\section{REFERÊNCIAS}

ARROYO, Miguel. Passageiros da noite: do trabalho para a EJA - Itinerários pelo direiro a uma vida justa. Petrópolis: Vozes, 2017.

BRANDÃO, Carlos Rodrigues. O que é educação. 20. ed. São Paulo: Brasiliense, 1996.

FREIRE, Ana Maria Araújo. Inédito-viável. In: STRECK, Danilo R.; REDIN, Euclides; ZITKOSKI, Jaime José. (Orgs). Dicionário Paulo Freire. Belo Horizonte: Autêntica, 2008. p. 231-234.

Paulo Freire: uma história de vida. 2. ed. rev. e atualizada. Rio de JaneiroSão Paulo: Paz e Terra, 2017.

FREIRE, Paulo. Ação cultural para a liberdade e outros escritos. 8. ed. Rio de Janeiro: Paz e Terra, 1987.

A importância do ato de ler: em três artigos que se completam. 51. ed. São Paulo: Cortez, 2011.

Conscientização. São Paulo. Cortez, 2016.

Educação como prática da liberdade. 22. ed. Rio de Janeiro, Paz e Terra, 1994.

Educação e atualidade brasileira. 2. ed. São Paulo: Cortez, 2012.

Pedagogia da autonomia. 51. ed. Rio de Janeiro: Paz e Terra, 2015.

2011.

Pedagogia da esperança: um reencontro com a pedagogia do oprimido. 17. ed. Rio de Janeiro: Paz e Terra,

Pedagogia da indignação: cartas pedagógicas e outros escritos. São Paulo: Ed. UNESP, 2000.

Pedagogia do oprimido. 44. ed. Rio de Janeiro: Paz e Terra, 2006.

Segunda carta: Do direito e do dever de mudar o mundo. In: Pedagogia da indignação: cartas pedagógicas e outros escritos. São Paulo: Ed. UNESP, 2000. p. 53-63.

GALEANO, Eduardo. As veias abertas da América Latina. 36. ed. Rio de Janeiro: Paz e Terra, 1994.

MÁRQUEZ, Gabriel García. A solidão da América latina. In: Eu não vim fazer um discurso. Rio de Janeiro: Record, 2011. p. 22-28.

SANTOS, Boaventura S. Para além do pensamento abissal: das linhas globais a uma ecologia dos saberes. In:

SANTOS, Boaventura S.; MENESES, Maria Paula (Orgs.). Epistemologias do sul. São Paulo: Cortez, 2010. p. $31-83$. 


\section{RESUMO}

O pretendido neste artigo é discutir a atualidade da obra de Paulo Freire para $\theta$ um projeto plural de "epistemologias do Sul" desde o continente latino-americano, ou seja, sua contribuição para um referencial teórico condizente com as nossas realidades e condição histórica. Percorrendo alguns dos seus escritos, produzidos em diferentes momentos da sua trajetória intelectual, mas observando a coerência seu legado, enfatizamos o valor da sua obra diante não apenas das necessidades referidas à educação escolar e popular, mas também para a tessitura de ações culturais conscientizadoras e formadoras da nossa presença no lugar e no mundo. Destacamos para tal, a concepção de educação transformadora em Paulo Freire e o valor estético da criação no seu pensamento.

Palavras-chave: Paulo Freire. Inédito-viável. Transformação social.

\section{BEING A BEING IN THE WORLD: HUMANIZATION IS A POETIC IN PAULO FREIRE}

\section{ABSTRACT}

The aim of this article is to discuss the contemporaneity of Paulo Freire's work for a pluralistic project of "epistemologies of the South" from the Latin American continent, i.e., its contribution for a theoretical reference consistant with our realities and historical condition. Going through his written material produced in different moments of his intelectual trajectory, but watching out the coherence of his legacy,we emphasize the value of his work not only concerning popular and school education needs, but also concerning conscious cultural acts that form our presence on the place and in the world. So, we highlight the conception of transforming education in Paulo Freire and the aesthetic value of creation in his thought.

Keywords: Paulo Freire. Inedited-viable. Social transformation.

\section{PARA SER UN SER EN EL MUNDO: LA HUMANIZACIÓN ES UNA POÉTICA EN PAULO FREIRE}

\section{RESUMEN}

Lo pretendido en este artículo es discutir la actualidad de la obra de Paulo Freire para un proyecto plural de "epistemologías del Sur" desde el continente latinoamericano, o sea, su contribución a un referencial teórico de acuerdo con nuestras realidades y condición histórica. Recorrendo a algunos de sus escritos, producidos en diferentes momentos de su trayectoria intelectual, pero observando la consistencia de su legado, enfatizamos el valor de su obra contra las necesidades a que se refiere la educación escolar e popular, así como para la tesitura de acciones culturales concientizadoras y formadoras de nuestra presencia en el lugar y en el mundo. Destacamos así, la concepción de educación transformadora en Paulo Freire y el valor estético de la creación en su pensamiento.

Palabras-clave: Paulo Freire. Inédito-viable. Transformación social. 